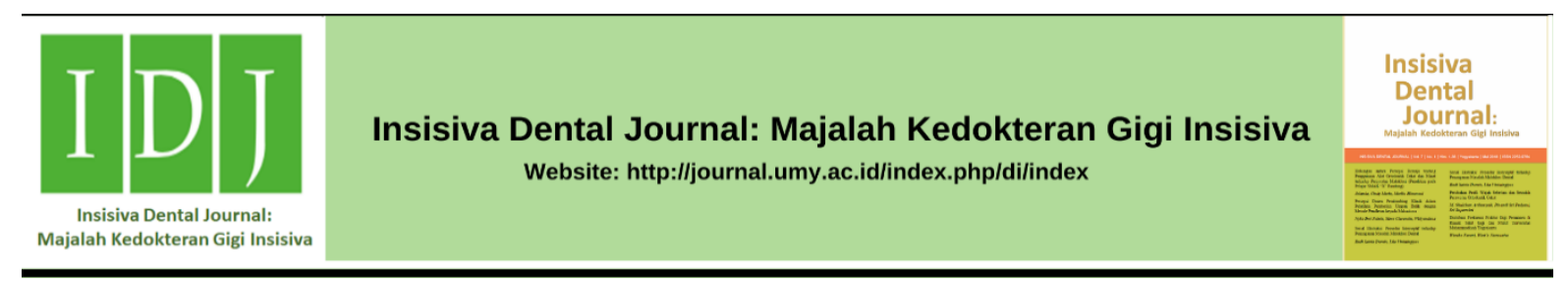

Research Article

\title{
Formularium Tata Laksana Preventif dan Promotif di Rumah Sakit Gigi dan Mulut Universitas Muhammadiyah Yogyakarta
}

Formulary of Preventive and Promotive Management in Dental and Oral Hospital Universitas Muhammadiyah Yogayakarta

\author{
Novitasari R. Astuti ${ }^{1, *}$, Pipiet O. Kusumastiwi ${ }^{1}$, Iwan Dewanto ${ }^{1}$, Adike D. Salecha ${ }^{2}$, Karlina Agustiyana ${ }^{2}$ \\ ${ }^{1}$ Departemen Ilmu Kesehatan Gigi Masyarakat, Program Studi Kedokteran Gigi, Fakultas Kedokteran dan Ilmu Kesehatan, Universitas \\ Muhammadiyah Yogyakarta, Jalan Brawijaya, Tamantirto, Kasihan, Bantul, Indonesia. \\ ${ }^{2}$ Program Studi Kedokteran Gigi, Fakultas Kedokteran dan Ilmu Kesehatan, Universitas Muhammadiyah Yogyakarta, Jalan Brawijaya, \\ Tamantirto, Kasihan, Bantul, Indonesia.
}

Received date: August 11 $1^{\text {st }}, 2019$; reviewed date: August 20 ${ }^{\text {th }}, 2019$; revised date: September $26^{\text {th }}, 2019$; accepted date: October $21^{\text {st }}, 2019$ DOI : $10.18196 /$ di. 8205

\begin{abstract}
Abstrak
Tahun 2018, 57,6\% penduduk Indonesia memiliki masalah kesehatan gigi dan mulut. Fakta ini menunjukkan perlunya upaya preventif dan promotif untuk menurunkan angka tersebut. Penelitian ini bertujuan membuat formularium tata laksana preventif dan promotif di Rumah Sakit Gigi dan Mulut Universitas Muhammadiyah Yogyakarta (RSGM UMY), menilai komunikasi terapeutik mahasiswa profesi, dan mengetahui efektivitas formularium tata laksana preventif dan promotif. Jenis penelitian ini adalah mixed method, jenis quasi eksperimental dengan rancangan pre-test post-test with control group dengan 140 responden yang dipilih dengan metode consecutive. Pengukuran skor plak dengan metode Loe dan Silness. Analisis data menggunakan paired sample t-test. Hasil penelitian menunjukkan terbentuknya standar formularium edukasi tata laksana preventif dan promotif, keterampilan komunikasi mahasiswa profesi terhadap pasien adalah baik (74\%), serta terdapat perbedaan indeks plak dengan nilai signifikansi 0,000. Kesimpulan penelitian menunjukkan adanya standar formularium edukasi tata laksana preventif dan promotif, keterampilan komunikasi mahasiswa profesi Dokter Gigi terhadap pasien di RSGM UMY adalah baik dan terdapat perbedaan indeks plak sebelum dan sesudah diberikan formularium edukasi tata laksana preventif dan promotif pada pasien perawatan scaling.
\end{abstract}

Kata Kunci: Formularium tata laksana preventif dan promotif; Indeks plak; Komunikasi terapeutik

\begin{abstract}
In 2018, 57.6\% of the Indonesia's population has oral and dental health problems. This fact showed the urgency for preventive and promotive efforts to reduce the percentage. This research aims to formulate preventive and promotive management procedures at the Dental and Oral Hospital of Universitas Muhammadiyah Yogyakarta (RSGM UMY), to assess the therapeutic communication of professional students, and to find out the effectiveness of preventive and promotive governance formularies. This research is a mixed-method, a quasi-experimental design with a pre-test and post-test with control group design. 140 respondents were selected by a consecutive method. Measurement of plaque scores was conducted using the Loe and Silness method. Data were analyzed by using paired sample t-test. The results showed that there was the formation of preventive and promotive management education formulary standards, communication skills of professional students to patients was good (74\%), and there were differences in the plaque with a significance value of 0,000. It can be concluded that there was a standard formulary of preventive and promotive management education, the communication skills of Dentistry profession students to patients at RSGM UMY were good, and there were differences in the plaque index before and after the formulary of education on preventive and promotive management in scaling treatment patients.
\end{abstract}

Keywords: Preventive and promotive governance formulary; Plaque index; Therapeutic communication

*Corresponding author, e-mail: ovi_umy@yahoo.com 
PENDAHULUAN

Penyakit gigi dan mulut masih banyak dikeluhkan oleh masyarakat Indonesia, tidak terkecuali karies dan penyakit periodontal. ${ }^{1}$ Besarnya angka karies gigi dan penyakit periodontal di Indonesia yang cenderung meningkat mencerminkan persepsi dan perilaku masyarakat tentang kebersihan dan kesehatan gigi dan mulut masih kurang. ${ }^{2}$ Riset Kesehatan Dasar (RISKESDAS) Kementrian Kesehatan RI tahun 2018 melaporkan bahwa penduduk Indonesia yang memiliki masalah kesehatan gigi dan mulut rerata 57,6\%. ${ }^{3}$ Fakta ini menunjukkan untuk menurunkan angka tersebut diperlukan upaya promotif dan preventif, tanpa mengabaikan kuratif dan rehabilitatif yang sesuai dengan paradigma sehat serta menjaga kebersihan gigi dan mulut sebagai perilaku pemeliharaan dari masing-masing individu. Perilaku kebersihan mulut tambahan seperti flossing dan menyikat interdental sangat direkomendasi meskipun bukti keefektifannya kurang. ${ }^{4}$ Kebersihan gigi dan mulut adalah kunci untuk mencegah dan menjaga kesehatan periodontal, termasuk mencegah karies gigi. ${ }^{5}$

Pemeliharaan kesehatan gigi dan mulut tersebut sangat erat kaitannya dengan kontrol plak atau menghilangkan plak secara teratur karena plak gigi merupakan salah satu faktor yang dominan dalam perkembangan penyakit periodontal dan karies. ${ }^{1,6}$ Data pasien pembersihan karang gigi (scaling) di RSGM UMY menjadi salah satu indikator keberhasilan perawatan scaling yakni penurunan indeks plak pada kunjungan mahasiswa profesi pada tahun 2017 terdapat 4062 orang, dengan rata-rata setiap bulan terdapat 339 orang. Salah satu tahapan dari perawatan scaling adalah pemberian Komunikasi Informasi dan Edukasi (KIE) dalam upaya preventif dan promotif oleh mahasiswa profesi. Sebagai dokter gigi selain memberikan perawatan pada individu pasien, juga harus mampu untuk fokus memberikan promosi kesehatan. $^{7}$
Berdasarkan hasil evaluasi yang telah dilakukan, tidak terdapat penurunan indeks plak yang signifikan antara kunjungan pertama dan kedua. Salah satu faktor yang dapat menyebabkan hal tersebut adalah beragamnya penyampaian KIE oleh mahasiswa profesi dan belum ada standar KIE setelah perawatan scaling dalam bentuk formularium tata laksana preventif dan promotif, oleh sebab itu penting dilakukan penyusunan formularium tata laksana preventif dan promotif di RSGM UMY.

Penelitian ini bertujuan membuat formularium tata laksana preventif dan promotif di RSGM UMY, menilai komunikasi terapeutik mahasiswa profesi, dan mengetahui efektivitas formularium tata laksana preventif dan promotif (indeks plak sebelum dan sesudah perawatan scaling).

\section{MATERIAL DAN METODE}

Jenis penelitian ini adalah penelitian mixed method, penelitian kuantitatif dan kualitatif. Penelitian kualitatif dilakukan sebelum intervensi yaitu pengumpulan data awal mengenai jalannya komunikasi terapeutik mahasiswa profesi dan pasien di RSGM UMY, penyusunan formularium tata laksana preventif dan promotif RSGM UMY dengan panel expert saat dan setelah intervensi. Panel expert saat intervensi berlangsung dilakukan untuk menilai jalannya implementasi formularium tata laksana preventif dan promotif di RSGM UMY. Sedangkan panel expert setelah intervensi dilakukan untuk melakukan evaluasi jalannya implementasi formularium tata laksana preventif dan promotif di RSGM UMY.

Penelitian kuantitatif dilakukan untuk membandingkan penurunan plak gigi pasien scaling di RSGM UMY sebelum dan sesudah intervensi serta menilai komunikasi terapeutik mahasiswa profesi dengan pasien. Penelitian kuantitatif yang dilakukan menggunakan rancangan eksperimental semu (quasi eksperimental) dengan pre-test post-test with control group 
design. Penelitian ini dilaksanakan di RSGM UMY.

Populasi pasien scaling di RSGM UMY dan subjek penelitian kuantitatif dengan kriteria inklusi yaitu umur 18 - 55 tahun, mendapatkan perawatan scaling, scaling dilakukan oleh mahasiswa profesi RSGM UMY. Kriteria eksklusi yaitu pasien tidak dapat hadir pada kunjungan ke-2, pasien tidak bersedia untuk menjadi subjek penelitian, pasien merupakan keluarga mahasiswa profesi.

Subjek penelitian sebanyak 105 mahasiswa profesi Dokter Gigi UMY dan 140 pasien scaling yang dipilih melalui metode consecutive dikelompokkan menjadi 2 kelompok, yaitu 70 kelompok kontrol dan 70 intervensi. Masing masing kelompok diperiksa plak gigi pasien pada kunjungan I dan II dan dibandingkan. Rancangan ini untuk mengetahui apakah implementasi formularium tata laksana preventif promotif dapat menurunkan indeks plak pasien scaling RSGM UMY dan untuk menilai komunikasi terapeutik mahasiswa profesi dengan pasien. Pengukuran skor plak dengan metode Loe dan Silness menggunakan kuesioner komunikasi terapeutik, form Indeks plak (Loe and Sillnes).

Masing - masing kelompok dilakukan pemeriksaan indeks plak gigi pasien pada kunjungan I dan II dan pada kelompok intervensi diberikan formularium edukasi tata laksana preventif dan promotif setelah perawatan scaling dilakukan dalam rentang waktu 15-30 hari. Waktu 15-30 hari tersebut tidak terlalu dekat dan tidak terlalu jauh sehingga dapat dilihat perbedaan antara skor pada pengukuran pertama dan pengukuran kedua. ${ }^{8}$ Analisis data menggunakan paired sample t-test.

\section{HASIL}

Karakteristik responden mahasiswa profesi dokter gigi yang diteliti yaitu mayoritas berusia 23 tahun (46,7\%) dan mayoritas berjenis kelamin perempuan $(76,2 \%)$. Keterampilan komunikasi mahasiswa profesi program pendidikan Dokter gigi UMY menunjukkan hasil sebagian besar responden mempunyai keterampilan komunikasi yang baik (74\%).

Berdasarkan pengumpulan data yang dilakukan dengan beberapa expert melalui Focus Group Discussion (FGD) dan wawancara dengan beberapa perwakilan mahasiswa profesi kedokteran gigi UMY dari setiap angkatan serta referensi jurnal dan textbook maka dapat ditetapkan suatu prosedur komunikasi teraputik antara mahasiswa dan pasien dalam bentuk formularium tata laksana preventif dan promotif khususnya pasien scaling di RSGM UMY.

Bentuk formularium edukasi pasca perawatan scaling pasien yang telah dimodifikasi peneliti adalah sebagai berikut: 1) Menyikat gigi minimal 2x sehari pagi setelah sarapan dan malam sebelum tidur. 2) Memilih sikat gigi dengan kepala sikat yang tidak terlalu kecil agar mudah diaplikasikan di rongga mulut (untuk dewasa dengan panjang $2,5 \mathrm{~cm}$ dan untuk anak-anak 1,5 cm). 3) Pegangan sikat fleksibel/mudah digenggam. 4) Bulu sikat yang lembut. 5) Menggunakan pasta gigi yang mengandung fluoride. 6) Ukuran pasta gigi sebesar biji jagung. 7) Mengganti sikat gigi setiap 3 - 4 bulan sekali atau segera diganti jika sudah mulai rusak. 8) Mengurangi konsumsi makanan dan minuman manis. 9) Mengurangi kebiasaan merokok dan jika memungkinkan berhenti merokok. 10) Kontrol 1 minggu setelah perawatan pembersihan karang gigi. 11) Periksa kesehatan gigi dan mulut setiap minimal 6 bulan sekali ke dokter gigi. ${ }^{9}$

Berdasarkan analisa data dengan menggunakan uji paired sample t-test didapatkan hasil nilai signifikansi 0,000 (p $<0,05$ ) yang berarti H0 ditolak. Hasil tersebut menunjukkan bahwa terdapat perbedaan indeks plak sebelum dan sesudah diberikan formularium edukasi tata laksana preventif dan promotif di RSGM UMY. Adapun rata - rata plak indeks mengalami penurunan sebelum 31,32 dan sesudah 18,89 . 


\section{PEMBAHASAN}

Berdasarkan hasil uji paired sample t-test didapatkan hasil nilai signifikansi $0,000$ ( $\mathrm{p}<0,05)$ yang menunjukkan bahwa terdapat perbedaan indeks plak sebelum dan sesudah perawatan scaling dengan pemberian formularium edukasi tata laksana preventif dan promotif pada pasien di RSGM UMY.

Keberhasilan formularium edukasi tata laksana preventif dan promotif dalam menurunkan indeks plak meningkat menjadi lebih baik dalam penelitian ini didukung oleh beberapa hal yaitu responden yang kooperatif saat dilakukan pemeriksaan dan memperhatikan dengan seksama informasi yang diberikan serta keterampilan komunikasi terapuetik yang jelas dan benar dari mahasiswa profesi saat menyampaikan edukasi tata laksana preventif dan promotif pasca perawatan scalling pada kunjungan pertama. Sebanyak 60-70\% diagnosa dan rencana perawatan medis adalah berdasarkan informasi dari hasil anamnesis. ${ }^{10}$ Hasil penelitian menunjukkan bahwa keterampilan komunikasi mahasiswa profesi Dokter Gigi UMY dengan pasien di RSGM sebanyak $74 \%$ berada dalam kategori baik.

Keberhasilan komunikasi dipengaruhi oleh beberapa faktor yakni kurangnya pengetahuan dan kemampuan tenaga medis dalam menerapkan komunikasi. ${ }^{11}$ Berdasarkan pengamatan yang dilakukan oleh peneliti, salah satu faktor yang mempengaruhi adalah adanya pendidikan dan pelatihan skills lab komunikasi yang diterapkan di pendidikan profesi Dokter Gigi UMY selama jenjang pendidikan S1. Kurangnya keterampilan komunikasi terapeutik dapat disebabkan oleh kurangnya pengalaman seorang tenaga medis. ${ }^{12}$ Evaluasi tentang efek komunikasi dokter gigi dengan pasien mempunyai korelasi yang signifikan dan menunjukkan bahwa komunikasi antar professional di bidang kedokteran gigi mempengaruhi kepuasan pasien. ${ }^{13}$
Pelatihan merupakan salah satu aspek yang dapat meningkatkan kemampuan konseling dan komunikasi yang lebih baik. $^{14}$ dan pengalaman mengikuti pelatihan komunikasi terapuetik memiliki hubungan yang cukup signifikan terhadap pelaksanaan komunikasi terapeutik dengan pasien. ${ }^{15}$ Penurunan indeks plak gigi disebabkan karena peneliti memberikan pendidikan kesehatan gigi dan mulut khususnya tentang cara menggosok gigi yang benar. ${ }^{16}$ Diantara 5 model kognitif untuk memprediksi menyikat gigi, flossing dan berkumur, teori perilaku yang direncanakan dan model pendekatan proses tindakan kesehatan adalah prediktor terbaik perilaku kesehatan gigi dan mulut individu. ${ }^{17}$ Pada penelitian ini, pemberian formularium edukasi tata laksana preventif dan promotif khususnya perawatan scalling pada pasien merupakan salah satu bentuk pendidikan kesehatan.

\section{KESIMPULAN}

Kesimpulan penelitian menunjukkan terbentuknya standar formularium edukasi tata laksana preventif dan promotif, keterampilan komunikasi mahasiswa profesi Dokter Gigi terhadap pasien di RSGM UMY adalah baik dan terdapat pengaruh yang signifikan formularium edukasi tata laksana preventif dan promotif terhadap indeks plak pasien perawatan scaling.

\section{DAFTAR PUSTAKA}

1. Thomson, W. M., Sheiham, A., \& Spencer, A. J. Sociobehavioral aspects of periodontal disease. Periodontol. 2000. 2012; 60(1), 54-63.

2. Valm, A. M. (2019). The structure of dental plaque microbial communities in the transition from health to dental caries and periodontal disease. J. Mol. Biol. 2019; 431(16): 29572969.

3. Kementerian Kesehatan Republik Indonesia. Hasil Utama RISKESDAS 
2018. Jakarta: Badan Penelitian dan Pengembangan Kesehatan; 2018; 9396.

4. Sambunjak, D., Nickerson, J. W., Poklepovic, T., Johnson, T. M., Imai, P., Tugwell, P., \& Worthington, H. V. Flossing for the management of periodontal diseases and dental caries in adults. Cochrane Database Syst. Rev. 2011; 12: CD008829.

5. Kumar, S., Tadakamadla, J., \& Johnson, N. W. Effect of toothbrushing frequency on incidence and increment of dental caries: a systematic review and meta-analysis. J. Dent. Res. 2016; 95(11: 1230-1236.

6. Mitchell, L., Mitchell, D. A., \& McCaul, L. Kedokteran Gigi Klinik. Edisi, 5. Terj. Jakarta: EGC. 2014; 186-209.

7. Gallagher, J., \& Field, J. C. The Graduating European DentistDomain IV: Dentistry in Society. Eur. J. Dent. Educ. 2017; 21(Suppl. 1): 2527.

8. Harris, R., Vernazza, C., Laverty, L., Lowers, V., Brown, S., Burnside, G., ... \& Steele, J. Presenting information on dental risk: PREFER study protocol for a randomised controlled trial involving patients receiving a dental check-up. Contemp. Clin. Trials Commun. 2018; 11: 1-9.

9. Nasfiannoor, M. Pendekatan Statistika Modern Untuk Ilmu Sosial. Jakarta: Salemba Humanika. 2009.

10. Rezaei, F., \& Askari, H. A. Checking the relationship between physicians' communication skills and outpatients' satisfaction in the clinics of Isfahan AlZahra (S) Hospital in 2011. J. Edu. Health Promot. 2014; 3: 105.

11. Diana, R. S., \& Ekowati, W. Hubungan Pengetahuan Komunikasi Terapeutik terhadap Kemampuan Komunikasi Perawata dalam Melaksanakan Asuhan Keperawatan di Rumah Sakit Elisabeth Purwokerto. Jurnal Keperawatan Soedirman. 2006; 1(2), 53-60.

12. Taviyanda, D. Perbedaan Persepsi Pasien terhadap Komunikasi Terapeutik antara Perawat Pegawai Tetap dengan Perawat Pegawai Kontrak di Ruang Dewasa Kelas III RS. Baptis Kediri. Jurnal Penelitian STIKES Kediri. 2010; 3(2), 72-77.

13. Hamasaki, T., Kato, H., Kumagai, T., \& Hagihara, A. Association between dentist - dental hygienist communication and dental treatment outcomes. J. Health Commun. 2017; 32(3), 288-297.

14. Kounenou, K., Aikaterini, K., \& Georgia, K. Nurses' communication skills: Exploring their relationship with demographic variables and job satisfaction in a Greek sample. Procedia. Soc. Behav. Sci. 2011; 30: 2230-2234.

15. Soelarso, H., Soebekti, R. H., \& Mufid, A. Peran komunikasi interpersonal dalam pelayanan kesehatan gigi (The role of interpersonal communication integrated with medical dental care). Dental Journal (Majalah Kedokteran Gigi). 2005; 38(3): 124-129.

16. Pantow, C. B., Warouw, S. M., \& Gunawan, P. N. Pengaruh Penyuluhan Cara Menyikat Gigi Terhadap Indeks Plak Gigi pada Siswa SD Inpres Lapangan. $e-G i G i$. 2014; 2(2): 1-6.

17. Dumitrescu, A. L., Dogaru, B. C., Duta, C., \& Manolescu, B. N. (2014). Testing five social-cognitive models to explain predictors of personal oral health behaviours and intention to improve them. Oral Health Prev. Dent. 2014; 12(4): 345-355. 